\title{
Determination of water-soluble elements in PM2.5, PM10, and PM2.5-10 collected in the surroundings of power plants
}

\author{
Elwira Zajusz-Zubek ${ }^{1, *}$, Anna Mainka ${ }^{1}$ and Konrad Kaczmarek ${ }^{2}$ \\ ${ }^{1}$ Department of Air Protection, Silesian University of Technology, 22B Konarskiego St., 44-100 \\ Gliwice, Poland \\ ${ }^{2}$ Institute of Mathematics, Silesian University of Technology, 23 Kaszubska St., 44-100 Gliwice, \\ Poland; E-Mail: Konrad.Kaczmarek@polsl.pl
}

\begin{abstract}
The analysis reported in this study was performed to characterize the concentrations and water-soluble content of trace elements (As, $\mathrm{Cd}, \mathrm{Co}, \mathrm{Cr}, \mathrm{Hg}, \mathrm{Mn}, \mathrm{Ni}, \mathrm{Pb}, \mathrm{Sb}$ and $\mathrm{Se}$ ) in PM2.5, PM10 and PM2.510 samples collected in the surroundings of power plants in southern Poland. The solubility of trace elements bound to PM2.5 and PM10 was higher than for PM2.5-10, and in most cases, significant differences were revealed in the relative percentage concentrations of the water-soluble fractions. The occurrence of $\mathrm{Cd}, \mathrm{Cr}, \mathrm{Mn}, \mathrm{Ni}, \mathrm{Pb}$ and $\mathrm{Se}$ in first PCA (Principal Component Analysis) factor (PC1) - indicate coal combustion processes as the potential source of these elements. Other factors indicate two further anthropogenic sources: the resuspension of road dust due to vehicular activities and waste burning in domestic sources - factor (PC2), and, soil dust sources affected by fugitive dust from the mining processes and unpaved roads, as well as transportation and deposition of coal-factor (PC3).
\end{abstract}

\section{Introduction}

The concentration and composition of airborne particulate matter (APM) at a specific location depends on a large number of natural and anthropogenic factors, such as local and regional PM sources, meteorological conditions and geographical situation [1,2]. Particles with diameters of below $10 \mu \mathrm{m}$ have various sources. They mainly originate from the resuspension of road dust, coal and oil combustion, and industrial processes $[3,4]$.

In the evaluation of the environmental impact of coal-fired power plants, PM is an important factor. Its hazardous potential results from the ability of dust to penetrate into an organism via the respiratory tracts, and from the presence of dangerous substances contained in the dust particles. Among the dangerous substances loaded on the PM, many studies have referred to the total content of hazardous air pollutants (HAPs), especially trace elements ( $\mathrm{As}, \mathrm{Be}, \mathrm{Cl}, \mathrm{Cr}, \mathrm{Cd}, \mathrm{Co}, \mathrm{Hg}, \mathrm{Mn}, \mathrm{Ni}, \mathrm{Pb}, \mathrm{Sb}$ and $\mathrm{Se}$ ) [5-7]. However, there is a shortage of data on the chemical forms of trace elements (chemical speciation) which

${ }^{*}$ Corresponding author: elwira.zajusz-zubek@,polsl.pl 
occur in APM [8-10]. In developing countries, energy processes based on coal - as well as coal pyrolysis - are the most significant sources of HAPs [11,12].

The evaluation of the potential toxicities of trace elements is based on the distributions of their chemical forms, as divided into four groups (highly mobile, mobile, less mobile and not mobile). Mobile elements are particularly bioavailable to the environment. The amount of potentially bioavailable trace elements in PM can be estimated from the water-soluble fraction and from the fraction obtained with a dilute salt by extraction [13-16]. Thus, investigations of the soluble or extractable elements in PM have attracted far greater attention in this field of study.

In our study, chemical fractionation was applied in order to characterize (1) the mobility of trace elements in respirable (PM2.5), inhalable (PM10) and coarse fractions (PM2.5-10), collected from areas near coal-fired power plants; and (2) principal component analysis (PCA), to identify the possible sources of these elements in this area.

\section{Material and Methods}

\subsection{Sampling Sites}

Due to the influence of the particular heating season, especially on domestic and municipal emissions, the sampling campaigns were only carried out during the summer season. Samples were collected from 28 May to 23 September 2014 (16 weeks), in the surroundings of four working power plants fired with hard coal. Each sampling campaign was divided into four sessions for each location. In order to collect a sufficient amount of PM (with diameters $<1,1-2.5$, and $2.5-10 \mu \mathrm{m}$ ), each session was conducted continuously for seven days. In total, there were 48 samples and 32 blanks (stored in the sampling area but not exposed).

All of the sampling points were located to the northeast of the selected power plants, in accordance with the dominant wind direction in the region. The distance of the points from their corresponding power plants was approx. $2 \mathrm{~km}$. The choice of a specific location was dependent on the possibility of locating the measuring apparatus on a particular estate with the permission of the owners.

The sampling points were all located in southern Poland. Three of them (P1, P3, and P4) were situated in the industrial macro-region of Upper Silesia, while P2 was situated approx. $70 \mathrm{~km}$ to the west of this macro-region. Figure 1 shows the study area and the sampling locations in the surroundings of the four selected power plants.

In each studied area, the amount of APM is generally associated with local pollutant sources. For all the sampling sites, the major source was the power plants, including the transportation and deposition of coal and fly ash. Other sources included industrial activities, the combustion of coal and wood for domestic cooking purposes, and vehicle transport. Additionally, points $\mathrm{P} 1$ and $\mathrm{P} 2$ were impacted by soil resuspension from agriculture activities and vehicle traffic on unpaved roads. Meanwhile, at points P3 and P4, there was an impact from the urban traffic from the neighboring cities (Katowice and Jaworzno). 


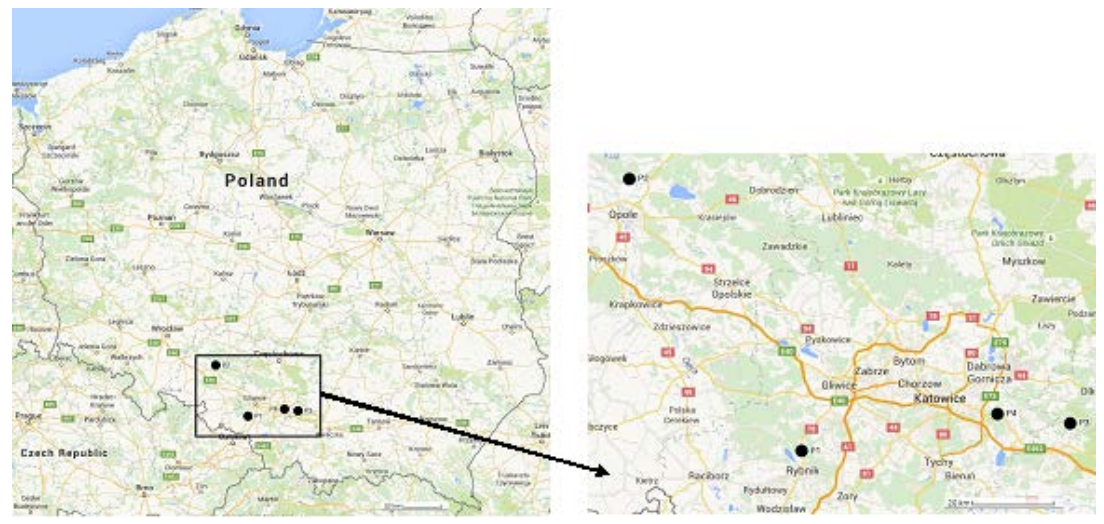

Fig. 1. Location of the sampling sites in southern Poland (Map data: (C2017 Google, ORION-ME).

\subsection{Sampling Method}

The methodology adopted here follows that of [13]. The samples were collected at sites P1P4, near four working power plants, using a three-stage impactor: a Dekati ${ }^{\circledR}$ PM10 impactor (Finland) with a flow rate of $30 \mathrm{dm}^{3} / \mathrm{min}$. The impactor differentiates particles into four size fractions with cut-off diameters of $<1,1-2.5,2.5-10$ and $>10 \mu \mathrm{m}$, respectively. The particles with diameters $>1 \mu \mathrm{m}$ were collected on polycarbonate membranes (Nuclepore, Whatman International Ltd., Maidstone, UK; diameter $25 \mathrm{~mm}$ ), while the backup filter material was made of Teflon (Pall International Ltd., New York, NY, USA; diameter $47 \mathrm{~mm}$ ). The average volume of air aspired by the filters was approx. $300 \mathrm{~m}^{3}$. Blank filters were stored in the sampling area. According to the manufacturer's information, the impactor is characterized by uncertainties below $2.8 \%$. The inlet tube was installed $1.5 \mathrm{~m}$ above the ground, which is important when considering human exposure. The membranes and filters were conditioned before and after sampling (temperature $20 \pm 1{ }^{\circ} \mathrm{C}$; relative humidity $50 \pm 5 \%$ ) for $48 \mathrm{~h}$, and weighted with a microbalance precision of $1 \mu \mathrm{g}$ (MXA 5/1, RADWAG, Radom, Poland).

\subsection{Chemical Analysis and Quality Control}

Three PM fractions (with cut-off diameters of 2.5 and $10 \mu \mathrm{m}$ ), collected in the surroundings of four working power plants, applied the sequential extraction procedure following [13]. The evaluation of the chemical forms of the trace elements underwent the procedure of leaching, based on the scheme described by Tessier et al. [17], and modified by Fernández Espinosa et al. [18], Sanchez-Rodas et al. [19] and Schleicher et al. [20]. The fractionation of PM $(2.5,10$ and $2.5-10 \mu \mathrm{m})$ separated the bound elements into four fractions. The first fraction (F1) covers soluble and exchangeable elements. The second fraction (F2) includes carbonates, oxides, and reducible elements. The third fraction (F3) contains elements bound to organic matter, oxidizable and sulphidic elements. The last fraction (F4) encloses residual elements.

For every fraction, the As, $\mathrm{Cd}, \mathrm{Co}, \mathrm{Cr}, \mathrm{Hg}, \mathrm{Mn}, \mathrm{Ni}, \mathrm{Pb}, \mathrm{Sb}$ and $\mathrm{Se}$ content was determined. The total content of each trace element was calculated as the sum of the four extraction steps $[18,21]$.

Determining the concentration of the various trace elements for each sample was carried out by inductively coupled plasma mass spectrometry (ICP-MS) (NexION 300D, PerkinElmer, Inc., Waltham, MA, USA). The instrument was equipped with a multiplier collector and a radio frequency power of $3 \mathrm{~kW}$ was applied to the plasma. 
All of the statistical analyses, including a univariate and multivariate analysis, as well as a principal component analysis, were performed using the statistical package, Statistica 10 (StatSoft, Tulsa, OK, USA). Non-parametric tests were undertaken to confirm the parametric results - that is, the corresponding non-parametric tests led to the same conclusions of significance/non-significance as the parametric tests. Throughout the study, a $p$-value of $<0.05$ was considered to indicate statistical significance.

\section{Results and Discussion}

\subsection{APM and Trace Element Concentrations}

In our study, the concentrations of trace elements in PM2.5, PM10 and PM2.5-10 (coarse fraction with particles of an aerodynamic diameter between 2.5 and $10 \mu \mathrm{m}$ ) were examined at the four locations (P1, P2, P3 and P4) in the surroundings of four working power plants (PP1, PP2, PP3 and PP4). To compare the trace element concentrations, the results showing their total content in PM2.5, PM10, and PM2.5-10 collected at all sites are presented in Table 2. The mean PM2.5, PM10 and PM2.5-10 concentrations determined at the four sampling sites P1-P4 were $13.10 \mu \mathrm{g} / \mathrm{m}^{3}$ (range $6.86-19.65 \mu \mathrm{g} / \mathrm{m}^{3}$ ), $16.33 \mu \mathrm{g} / \mathrm{m}^{3}$ (range $10.39-22.08 \mu \mathrm{g} / \mathrm{m}^{3}$ ) and $3.23 \mu \mathrm{g} / \mathrm{m}^{3}$ (range $2.27-4.56 \mu \mathrm{g} / \mathrm{m}^{3}$ ), respectively.

Table 2. The PM mass concentrations $\left(\mu \mathrm{g} / \mathrm{m}^{3}\right)$ and trace element concentrations $\left(\mathrm{ng} / \mathrm{m}^{3}\right)$ of PM2.5, PM10 and PM2.5-10.

\begin{tabular}{|c|c|c|c|c|c|c|c|c|c|c|c|}
\hline \multirow{2}{*}{\multicolumn{2}{|c|}{ PM $2.5, \mu \mathrm{g} / \mathrm{m}^{3}$}} & \multicolumn{10}{|c|}{ Elements concentration, $\mathrm{ng} / \mathrm{m}^{3}$} \\
\hline & & \multirow{2}{*}{$\begin{array}{c}\text { As } \\
0.85\end{array}$} & \multirow{2}{*}{\begin{tabular}{|c|} 
Cd \\
0.78
\end{tabular}} & \multirow{2}{*}{$\begin{array}{c}\text { Co } \\
0.18\end{array}$} & \multirow{2}{*}{$\begin{array}{c}\mathbf{C r} \\
29.85\end{array}$} & \multirow{2}{*}{$\begin{array}{l}\mathbf{H g} \\
0.56\end{array}$} & \multirow{2}{*}{$\begin{array}{l}\text { Mn } \\
8.08\end{array}$} & \multirow{2}{*}{$\begin{array}{c}\mathbf{N i} \\
3.01\end{array}$} & \multirow{2}{*}{$\begin{array}{c}\mathbf{P b} \\
17.00\end{array}$} & \multirow{2}{*}{$\begin{array}{c}\mathbf{S b} \\
1.13\end{array}$} & \multirow{2}{*}{$\begin{array}{c}\mathbf{S e} \\
7.95\end{array}$} \\
\hline Average & 13.10 & & & & & & & & & & \\
\hline Min & 6.86 & 0.37 & 0.27 & 0.04 & 16.21 & 0.04 & 4.58 & 0.38 & 9.70 & 0.28 & 1.09 \\
\hline Max & 19.65 & 1.34 & 1.07 & 0.32 & 43.51 & 1.10 & 10.99 & 7.13 & 32.73 & 2.47 & 14.77 \\
\hline SD & 3.54 & 0.29 & 0.21 & 0.14 & 1 & 0.51 & 1.91 & 2.27 & 54 & 0.71 & 6.51 \\
\hline \multicolumn{12}{|c|}{$\mathrm{PM} 10, \mu \mathrm{g} / \mathrm{m}^{3}$} \\
\hline Average & 16.33 & 0.89 & 0.99 & 0.27 & 44.64 & 0.83 & 11.73 & 4.12 & 21.21 & 1.29 & 11.39 \\
\hline Min & 10.39 & 0.40 & 0.36 & 0.06 & 24.19 & 0.07 & 6.88 & 0 & 11.76 & 0.32 & 1.27 \\
\hline Max & 22.08 & 1.40 & 1.32 & 0.48 & 65.22 & 1.61 & 15.84 & 8.19 & 35.34 & 2.66 & 21.46 \\
\hline SD & 3.18 & 0.30 & 0.27 & 0.21 & 20.42 & 0.77 & 2.72 & 3.02 & 7.25 & 0.73 & 9.92 \\
\hline \multicolumn{12}{|c|}{ PM2.5-10, $\mu \mathrm{g} / \mathrm{m}^{3}$} \\
\hline Average & 3.23 & 0.04 & 0.21 & 0.09 & 14.80 & 0.27 & 3.65 & 1.11 & 4.21 & 0.16 & 3.44 \\
\hline Min & 2.27 & 0.03 & 0.06 & 0.02 & 7.98 & 0.02 & 2.09 & 0.14 & 2.05 & 0.05 & 0.15 \\
\hline Max & 4.56 & 0.06 & 0.38 & 0.16 & 21.71 & 0.53 & 5.18 & 3.06 & 12.62 & 0.24 & 6.83 \\
\hline SD & 0.63 & 0.01 & 0.12 & 0.07 & 6.84 & 0.26 & 1.01 & 1.05 & 3.02 & 0.08 & 3.42 \\
\hline
\end{tabular}

Generally, among the trace elements, the highest concentrations in all the determined PM fractions were revealed to be of $\mathrm{Cr}$ and $\mathrm{Pb}$. The similar distribution of trace elements in all PM fractions can be explained by the high share of PM2.5 in PM10 (79.04 $\pm 7.60 \%)$. Considering the total concentrations of different trace elements in PM2.5 and PM10, there were no significant differences $(p>0.05)$ for $\mathrm{As}, \mathrm{Co}, \mathrm{Hg}, \mathrm{Ni}, \mathrm{Pb}, \mathrm{Sb}$, and $\mathrm{Se}$, while the total concentrations of $\mathrm{Cd}, \mathrm{Cr}$ and $\mathrm{Mn}$ differed significantly ( $p=0.001-0.05)$. Comparing the total concentrations of trace elements in PM2.5-10 with PM2.5 or PM10 generally, significant differences $(p<0.05)$ were observed. Only $\mathrm{Hg}$ revealed similar concentration in PM2.5 and in the coarse fraction (PM2.5-10). 


\subsection{Soluble Fraction in APM}

There is actually a widespread agreement that information about the mass and total content of the trace elements in APM is necessary but insufficient, in order to evaluate the overall pollution and hazard levels. Figure 2 illustrates the distribution of the water-soluble fraction in the total concentrations of $\mathrm{As}, \mathrm{Cd}, \mathrm{Co}, \mathrm{Cr}, \mathrm{Hg}, \mathrm{Mn}, \mathrm{Ni}, \mathrm{Pb}, \mathrm{Sb}$, and $\mathrm{Se}$ extracted from PM2.5, PM10 and PM2.5-10. Generally, the solubility was higher for PM2.5 and PM10 than for PM2.5-10, and in some cases, there were significant differences in the relative percentage concentrations for the water-soluble fractions. The fractionation data indicate high average substantial percentages of As (95.4\%), Sb (57.0\%), Cd (50.1\%), Mn (38.2\%) and $\mathrm{Pb}$ (35.2\%) in PM2.5, and As (93.9\%), Sb (51.3\%), Cd (44.3\%), Mn (34.2\%) and $\mathrm{Pb}$ (28.9\%) in PM10. In PM2.5-10, the highest contribution was also of As $(62.1 \%)$ and the following was $\mathrm{Mn}(22.7 \%)$. The concentrations of the water-soluble fractions of trace elements in PM2.5 and PM10 were only significantly different $(p<0.05)$ for $\mathrm{Co}$ and $\mathrm{Hg}$, whereas the water-soluble concentrations of trace elements in PM2.5-10 in comparison with PM2.5 and PM10 were significantly different $(p<0.05)$ for all the elements except $\mathrm{Hg}$ between coarse (PM2.5-10) and fine (PM2.5) fractions.

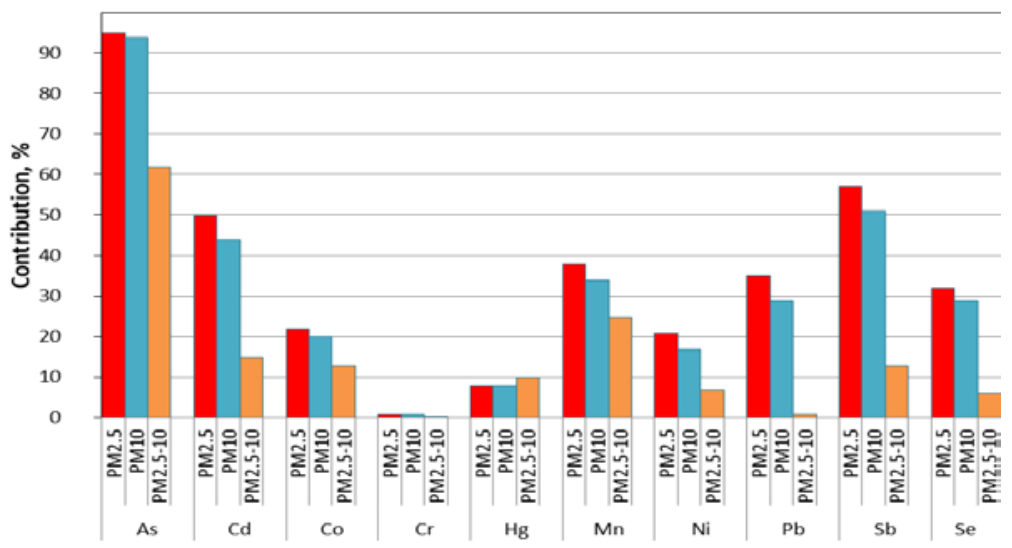

Fig. 2. The contribution of water-soluble trace elements in PM2.5, PM10 and PM2.5-10 samples collected from areas near the coal-fired power plants.

Similar studies on the elemental composition of the water-soluble fraction of PM2.5 samples collected in Greek cities were conducted by Manousakas et al. [8]. A substantial percentage ( $\geq 30 \%$ ) of the $\mathrm{Cd}, \mathrm{V}, \mathrm{Zn}, \mathrm{Cu}, \mathrm{Pb}$, and Ni displayed water-soluble characteristics in the samples collected in a coastal city, and the same was true of the As, $\mathrm{Cd}, \mathrm{Mn}, \mathrm{Ni}$ and $\mathrm{Pd}$ in samples collected near lignite power plants and mines. In our study, the water-soluble fraction of $\mathrm{Cd}, \mathrm{Mn}$, and $\mathrm{Pb}$ also contributed considerably $(>30 \%)$ to the total concentrations, in contrast to $\mathrm{Ni}$, for which the contribution of the water-soluble fraction was far lower (7.4\%). However, the Greek results cannot be directly compared with our study (of hard coal-fired power plants), due to the different emission profiles of lignite-fired power plants.

A significant percentage ( $>30 \%$ ) of water-soluble elements $-\mathrm{Cd}, \mathrm{Mn}, \mathrm{Pb}$, and $\mathrm{Sb}-$ was also reported by Sarti et al. [9] in PM2.5 collected near municipal waste incinerators (in the Bologna area). At the same time, the authors state that among the various combustion processes, waste incineration didn't seem to be the main source of these soluble metals in PM2.5. During a five-year field study in the peri-urban area of Ferrara, in northern Italy, Canepari et al. [22] studied the concentration and solubility of trace elements contained in fine (PM2.5) and coarse (PM2.5-10) fractions. The results show similar extraction 
percentages of the following elements in the fine (PM2.5) fraction: $\mathrm{As}, \mathrm{Cd}, \mathrm{Mn}, \mathrm{Pb}$, and $\mathrm{Sb}$. They emphasize that the solubility for PM2.5 was higher than that for PM2.5-10 and that in some cases there were significant differences in the relative percentage concentrations for the extracted and the residue fractions $[22,23]$.

\subsection{Principal Component Analysis (PCA)}

In order to determine the associations between the elements generated by diverse emission sources, PCA was applied to identify the possible sources of water-soluble trace elements in the PM2.5-10 samples. By using chemical fractionation data instead of total element content, PCA can evaluate emission sources with higher selectivity [23]. The relationships between the 10 trace elements are readily seen as a 3-D plot of the PCA loadings (Fig. 3).

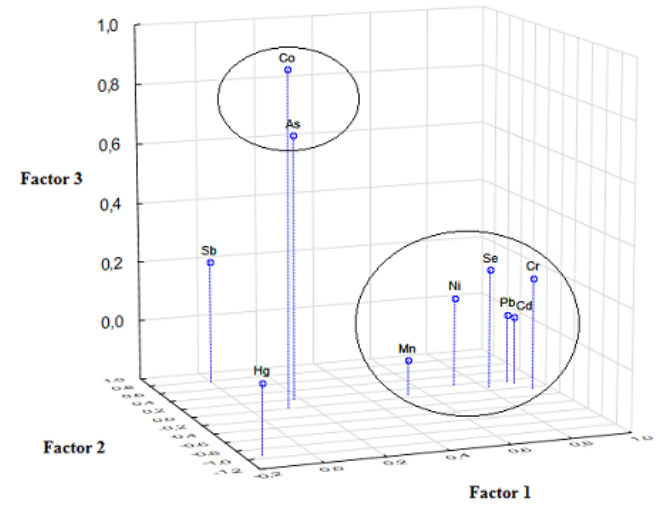

Figure 3. PCA loading 3-D plot (PC1 vs. PC2 vs. PC3) for 10 trace elements.

Three factors were obtained, accounting for $70.9 \%$ of the total variance:

(1) PC1 with high loadings of $\mathrm{Cd}, \mathrm{Cr}, \mathrm{Mn}, \mathrm{Ni}, \mathrm{Pb}$, and $\mathrm{Se}$;

(2) $\mathrm{PC} 2$ with high loadings of $\mathrm{Hg}$ and $\mathrm{Sb}$; and

(3) PC3, which includes As and Co.

The first component $(\mathrm{PC} 1)$ contributed $40.6 \%$ of the total variance. It is interesting to note that two groups of elements - Se- $\mathrm{Cr}$ and $\mathrm{Cd}-\mathrm{Pb}$ - are linked to each other at a higher level than other elements. This is compatible with results from previous studies the results [24,25], demonstrating that $\mathrm{Cd}$ and $\mathrm{Pb}$ can be reliably linked to fossil fuel burning (oil and coal). Moreover, in the case of $\mathrm{Cd}$ and $\mathrm{Pb}$, the link between these elements can be attributed to an association that extends far beyond direct industrial combustion [25].

The second component (PC2) contributed $16.0 \%$ of the variance, and included $\mathrm{Hg}$ and $\mathrm{Sb}$. However, the lack of association between $\mathrm{Hg}$ and $\mathrm{Sb}$ (or any other elements), observed in the opposite signs of PC2 loadings, indicate separate emission sources. $\mathrm{Hg}$ can be distributed from primary and secondary anthropogenic sources. The primary sources are mining, extraction and the burning of fossil fuels that contain $\mathrm{Hg}$ as a trace contaminant. The secondary anthropogenic sources are those in which emissions occur through the intentional use of mercury, including mercury use in industrial processes and waste incineration. The largest single source category of anthropogenic mercury emission into the air is the stationary combustion of coal, associated with energy or heat production in major power plants [26]. Nevertheless, it might indicate the influence of sources other than coal combustion. Bearing in mind the general problem in the region whereby low-quality fuels (biomass, culm or even refuse) are procured and burned for domestic purposes, the main source of water-soluble $\mathrm{Hg}$ in the coarse fraction could be waste incineration. In general, $\mathrm{Sb}$ 
is naturally present in soil [27]; hence, anthropogenic sources can be attributed to the resuspension of road dust, due to vehicular activities like brake wear [28,29]. In the region, $\mathrm{Sb}$ is also emitted from long-term mining and smelting activities [30]. Moreover, Sb revealed an intermediate degree of similarity to As and Co.

The third component (PC3) contributed about $14.3 \%$ of the variance. It essentially constitutes a loading of $\mathrm{Co}$ and As (to a lesser extent). As is regarded as a marker element of coal combustion and coke-making processes [31,32]; however, the PCA doesn't confirm this source. It would seem that the As in the water-soluble fraction originated from a source other than coal combustion processes. The presence of $\mathrm{Co}$ in soil may originate from anthropogenic activities, such as the application of cobalt-containing sludge or phosphate fertilizers, the disposal of cobalt-containing wastes, and the atmospheric deposition from activities such as mining, smelting, refining, and combustion [33]. Dai et al. [32] matched Co to soil dust. In addition, the PC 3 component might point to soil dust sources affected by fugitive dust from the mining processes and unpaved roads, as well as transportation and the deposition of coal.

\section{Conclusions}

A chemical extraction procedure coupled with ICP-MS was used for the characterization of the water-soluble elements contained in PM2.5, PM10 and PM2.5-10 samples, collected in the surroundings of hard coal-fired power plants in southern Poland. The results included the concentration, trace element composition and water solubility of the APM. The average concentration levels of PM2.5, PM10 and PM2.5-10 were $13.10 \mu \mathrm{g} / \mathrm{m}^{3}, 16.33 \mu \mathrm{g} / \mathrm{m}^{3}$ and $3.23 \mu \mathrm{g} / \mathrm{m}^{3}$, respectively.

The solubility of trace elements bound to PM2.5 and PM10 was higher than for PM2.5-10, and in most cases revealed significant differences in the relative percentage concentrations of the water-soluble fractions.

Principal component analysis (PCA) was performed on the water-soluble elements to identify the possible sources of these elements in this area. The occurrence of $\mathrm{Cd}, \mathrm{Cr}, \mathrm{Mn}$, $\mathrm{Ni}, \mathrm{Pb}$ and $\mathrm{Se}$ in one PCA factor (PC1), indicated coal combustion processes as a potential source of these elements.

Second (PC2) and third (PC3) components were loaded with $\mathrm{Hg}$ and $\mathrm{Sb}$, and $\mathrm{As}$ and $\mathrm{Co}$, respectively. Therefore, they can be attributed to other anthropogenic sources. PC2 could have been contributed to the resuspension of road dust due to vehicular activities, and waste burning in domestic sources. Meanwhile, PC3 points to soil dust sources affected by fugitive dust from the mining processes and unpaved roads, as well as the transportation and the deposition of coal.

In our opinion, to better interpret the results, it is worth to use chemical fractionation data instead of total element content, so the PCA is able to evaluate emission sources with a higher selectivity.

Acknowledgements: this work was supported by the Faculty of Power and Environmental Engineering, Silesian University of Technology (statutory research). All the results used in this paper have received funding from the National Science Centre Poland under grant 2012/05/B/ST10/00524.

\section{References}

1. A. Mues, A. Manders, M. Schaap, L. H. van Ulft, E. van Meijgaard, P. Builtjes, Atmos. Environ. 80, 232 (2013)

2. G. Titos, H. Lyamani, M. Pandolfi, A. Alastuey, L. Alados-Arboledas, Atmos. Environ. 89, 593 (2014) 
3. Y. Cheng, S. Lee, Z. Gu, K. Ho, Y. Zhang, Y. Huang, J. C. Chow, J. G. Watson, J. Cao, R. Zhang, Particuology 18, 96 (2015)

4. B. Srimuruganandam, S. M. Shiva Nagendra, Sci. Total Environ. 433, 8 (2012)

5. A. Mainka, E. Zajusz-Zubek, K. Kaczmarek, Int. J. Environ. Res. Public Health 12, 7990 (2015)

6. K. Mohiuddin, V. Strezov, P. F. Nelson, E. Stelcer, Atmos. Environ. 83, 72 (2014)

7. C. Petaloti, A. Triantafyllou, T. Kouimtzis, C. Samara, Chemosphere 65, 2233 (2006)

8. M. Manousakas, H. Papaefthymiou, K. Eleftheriadis, K. Katsanou, Sci. Total Environ. 493, 694 (2014)

9. E. Sarti, L. Pasti, M. Rossi, M. Ascanelli, A. Pagnoni, M. Trombini, M. Remelli, Atmos. Pollut. Res. 6, 708 (2015)

10. E. Zajusz-Zubek, A. Mainka, Z. Korban, J. S. Pastuszka, Atmos. Pollut. Res. 6, 1 (2015)

11. J. Konieczyński, E. Zajusz-Zubek, Arch. Environ. Prot. 37, 3 (2011)

12. J. Konieczyński, E. Zajusz-Zubek, M. Jabłońska, Sci. World J. 2012, 1 (2012)

13. E. Zajusz-Zubek, K. Kaczmarek, A. Mainka, Int. J. Environ. Res. Public Health 12, 13085 (2015)

14. E. Zajusz-Zubek, Evaluation of Forms in Which Occur Selected Trace Elements in Suspended Dust (PM10) and Respirable Fraction (PM2.5) in the Surroundings of CoalFired Power Plants and Coking Plants in the Non-Heating Season (Publishing House of Silesian University of Technology, Gliwice, 2016)

15. S. Yadav, P. G. Satsangi, Environ. Monit. Assess. 185, 7365 (2013)

16. P. Sipos, C. Choi, Z. May, Chemie Der Erde - Geochemistry 76, 481 (2016)

17. A. Tessier, P. G. C. Campbell, M. Bisson, Anal. Chem. 51, 844 (1979)

18. A. J. Fernández Espinosa, M. Ternero Rodríguez, F. J. Barragán De La Rosa, J. C. Jiménez Sánchez, Atmos. Environ. 36, 773 (2002)

19. D. Sanchez-Rodas, A. Sanchez De La Campa, V. Oliveira, J. De La Rosa, J. Inorg. Biochem. 108, 112 (2012)

20. N. J. Schleicher, S. Norra, F. Chai, Y. Chen, S. Wang, K. Cen, Y. Yu, D. Stüben, Atmos. Environ. 45, 7248 (2011)

21. P. Richter, P. Griño, I. Ahumada, A. Giordano, Atmos. Environ. 41, 6729 (2007)

22. S. Canepari, M. L. Astolfi, C. Farao, M. Maretto, D. Frasca, M. Marcoccia, C. Perrino, Environ. Sci. Pollut. Res. 21, 4010 (2014)

23. S. Canepari, A. Pietrodangelo, C. Perrino, M. L. Astolfi, M. L. Marzo, Atmos. Environ. 43, 4754 (2009)

24. Y. Zhai, X. Liu, H. Chen, B. Xu, L. Zhu, C. Li, G. Zeng, Sci. Total Environ. 493, 109 (2014)

25. S. M. Enamorado-Báez, J. M. Gómez-Guzmán, E. Chamizo, J. M. Abril, Atmos. Res. 155, 118 (2015)

26. E. G. Pacyna, J. M. Pacyna, K. Sundseth, J. Munthe, K. Kindbom, S. Wilson, F. Steenhuisen, P. Maxson, Atmos. Environ. 44, 2487 (2010)

27. C. A. Tylenda, D. W. Sullivan, Handbook on the Toxicology of Metals (Elsevier, 2015)

28. P. Pant, R. M. Harrison, Atmos. Environ. 77, 78 (2013)

29. F. Fujiwara, R. J. Rebagliati, J. Marrero, D. Gómez, P. Smichowski, Microchem. J. 97, $62(2011)$

30. W. Rogula-Kozłowska, K. Klejnowski, P. Rogula-Kopiec, B. Mathews, S. Szopa, Bull. Environ. Contam. Toxicol. 88, 722 (2012)

31. A. B. Vicente, T. Sanfeliu, M. M. Jordan, J. Environ. Manage. 108, 92 (2012)

32. Q.-L. Dai, Aerosol Air Qual. Res. 2015, 875 (2015)

33. D. Lison, Handbook on the Toxicology of Metals (Elsevier, 2015) 